\title{
Sağlık ve Sosyal Hizmet Çalışanları Örnekleminde Genel Öz-Yeterlik Ölçeği'nin Yapı Geçerliliğinin Doğrulayıcı Faktör Analizi ile İncelenmesi
}

\section{The Evaluation of Construct Validity of the General Self-Efficacy Scale in Health and Social Workers' Sample with Confirmatory Factor Analysis}

\author{
Şükrü Anıl Toygar a, ${ }^{\text {a }}$, Mehmet Kırlıoğlu ${ }^{\text {b }}$ \\ ${ }^{a}$ Doktor Öğretim Üyesi, Selçuk Üniversitesi, Hemşirelik Fakültesi, Hemşirelikte Yönetim Anabilim Dalı, Konya/TÜRKIYY. \\ ORCID: 0000-0002-3444-3243 \\ ${ }^{\mathrm{b}}$ Mehmet Kırlığlu, Necmettin Erbakan Üniversitesi, Sağlık Bilimleri Fakültesi, Sosyal Hizmet Bölümü, Konya/TÜRKİYE. \\ ORCID: 0000-0003-0130-0841
}

\section{MAKALE BİLGİSI}

Makale Geçmişi:

Başvuru tarihi: 03 Ocak 2020

Düzeltme tarihi: 02 Kasım 2020

Kabul tarihi: 10 Kasım 2020

Anahtar Kelimeler:

Genel Öz-Yeterlik

Sağlık ve Sosyal Hizmet Çalışanları

Doğrulayıcı Faktör Analizi (DFA)

\section{ART ICLE INFO}

\section{Article history:}

Received 03 January 2020

Received in revised 02 November 2020

Accepted 10 November 2020

\section{Keywords:}

General Self-Efficiacy

Health and Social Service Employee

Comfirmatory Factor Analysis (CFA)
ÖZ

Bu çalışmada Aypay (2010) tarafindan Türkçeye uyarlanan Genel Öz-Yeterlik Ölçeği’ne (GÖYÖ) ait modelin sağlık ve sosyal hizmet çalışanları örnekleminde Doğrulayıcı Faktör Analizi (DFA) ile doğrulanması gerçekleştirilmiştir. Araştırmaya katılanların \%58,8'i kadın, \%50,3’ü evli, \%82,3’ü lisans mezunu, \%27,2'si hemşire, \%26,2'si idari personel, \%20,8'1 sosyal hizmet çalışanıdır. DFA'ya ait uyum indeksleri incelendiğinde $x^{2}(92,50) / \mathrm{sd}(31)=2,98 ; \mathrm{CFI}=0,98 ; \mathrm{GFI}=0,96$; AGFI $=0,92 ;$ IFI $=0,98 ;$ RMSEA $=0,071 ;$ RMR $=0,013 ;$ SRMR $=0,039 ; \mathrm{NFI}=0,97 ; \mathrm{NNFI}=0,97$ sonuçları elde edilmiştir. DFA sonucunda GÖYÖ’ye ilişkin elde edilen $t$ değerlerinin $p<0,01$ düzeyinde anlamlı olduğu tespit edilmiştir. CFI, GFI, IFI, RMSEA, RMR, SRMR, NFI ve NNFI değerlerinin literatürde belirtilen mükemmel uyum değerlerinin, $\mathrm{x}^{2} / \mathrm{sd}$ ve AGFI değerlerinin ise kabul edilebilir değerin üzerinde olduğu sonucuna ulaşılmıştır. Çalışma sonucunda Aypay (2010) tarafından Türkçeye uyarlanan ölçeğin sağlık ve sosyal hizmet çalışanları üzerinde uygulanabileceği sonucuna ulaşılmıştır.

\section{A B S T R A C T}

In this study, General Self-Efficacy Scale (GSES), which was adapted to Turkish by Aypay (2010), was confirmed by performing Confirmatory Factor Analysis (CFA) in the sample of health and social workers. $58.8 \%$ of the participants were women, $50.3 \%$ were married, $82.3 \%$ were undergraduate graduates, $27.2 \%$ were nurses, $26.2 \%$ were administrative staff and $20.8 \%$ were social workers. When the fit indexes of CFA were examined, the results were obtained as $\mathrm{x}^{2}(92,50) / \mathrm{sd}(31)=2,98 ; \mathrm{CFI}=0,98 ; \mathrm{GFI}=0,96 ; \mathrm{AGFI}=0,92 ; \mathrm{IFI}=0,98 ; \mathrm{RMSEA}=0,071 ; \mathrm{RMR}=0,013$; $\mathrm{SRMR}=0,039$; NFI=0,97; NNFI=0,97. $\mathrm{T}$ values obtained after CFA for GSES were found to be significant at $\mathrm{p}<0.01$ level. It has been concluded that the excellent fit values of CFI, GFI, IFI, RMSEA, RMR, SRMR, NFI and NNFI values in the literature was and $x^{2} /$ sd while AGFI values are above acceptable values. As a result of the study, it was concluded that the scale adapted to Turkish by Aypay (2010) can be applied to health and social workers.

\section{Giriş}

Öz-yeterlik kavramı, kişinin belirli durumsal talepleri karşılamak için gereken motivasyonu, bilişsel kaynakları ve eylem yollarını harekete geçirme yeteneklerine olan inancı olarak tanımlanmaktadır (Wood ve Bandura, 1989: 408). Bir başka tanıma göre ise bireyin birbirinden farklı durumlarında gerekli performansı gerçekleştirmedeki genel yeterliğine olan inancı (Eden, 2001) ya da o performansı gösterebilme yeteneklerinin birey tarafindan algılanması olarak tanımlanmaktadır (Judge vd., 1998: 170). Bununla birlikte öz-yeterlik ileriye dönük ve operasyonel niteliktedir (Bandura, 1997). Davranışı etkilemenin temel faktörü olan algılanan öz-yeterlik, yani insanların istenen bir sonuca

\footnotetext{
*Sorumlu yazar/Şükrü Anıl Toygar

e-posta: sanil.toygar@selcuk.edu.tr
} 
ulaşmak için gereken belirli bir eylemi gerçekleştirme yeteneklerine inanmaları şeklinde ifade edilebilir (Luszczynska vd., 2005). Dolayısıyla, algılanan öz-yeterlik ise yeterlik temelli, ileriye dönük ve eyleme bağl1 bir kavram olarak tanımlanabilir. Genel öz-yeterlik olarak tanımlanan bu kavram, insanların ne kadar etkili olduklarına karar verdikleri çeşitli işlev alanlarındaki genellemeyi içermektedir (Bandura, 1997).

Literatürde öz-yeterlik kavramına ek olarak genellikle göreve veya alana özgü olarak anlaşılmakla birlikte, stresli durumlarla etkili bir şekilde başa çıkmak için geniş ve istikrarlı bir kişisel yeterlik duygusuna atıfta bulunan genelleştirilmiş bir öz-yeterlik duygusu da kavramlaşmıştır (Schwarzer ve Jerusalem, 1995). Genel öz-yeterlik kavramı ise evrensel bir yapıdadır, yani tüm bireylerin doğasında var olan temel bir inancı karakterize etmektedir. Kişisel eylemlerle etki yaratmanın kültürler arasında ortak olmasina dayanmaktadır (Bandura, 2002). Algılanan özyeterlik ve algılanan yeterlik bir dereceye kadar kişisel yeteneklere olan inanç ile ilgilidir. Verilen görev taleplerini yönetmek için kişisel etkililiği değerlendirirken, bireyler sadece bilişsel ve davranışsal becerilerini değil, tehdit ve zorluklar karşısında motivasyonlarını ve stres ve cesaretlerini yönetme becerilerini de dikkate almak zorundadırlar (Zimmerman, 1995: 216). Sosyal bilișsel teori, açıklanan bu inançların kökenlerini, mekanizmalarını ve farklılaşan etkilerini açıklamakta ve bunların nasıl yaratılacağı ve geliştirileceği konusunda kılavuzlar sağlamaktadır. Sosyal bilişsel teoriye göre insan motivasyonu ve eylemleri önceden düşünülerek yoğun bir șekilde düzenlenmektedir (Zimmerman, 1995: 216-217).

Sosyal bilişsel teoriye göre (Bandura, 1986), öz-yeterlik inançları üç boyuta göre değişmektedir: (a) seviye veya büyüklük (belirli görev zorluk seviyesi), (b) güç (belirli bir görev seviyesini başarılı bir şekilde yerine getirmenin kesinliği) ve (c) genellik (büyüklük ve güç inançlarının görevler ve durumlar arasinda genelleme derecesi).

Öz-yeterlik teorisi, bu alt süreçlerin tamamını hem bireysel hem de kolektif düzeyde ele almaktadır (Bandura, 1997).

Öz-yeterlik inanç sistemini daha geniş bir sosyo-bilişsel teoriye yerleştirerek, çeşitli bulguları farklı işlev alanlarına entegre edebilir. Bir teorinin değeri nihayetinde istenen değişiklikleri üretmek için verdiği yöntemlerin gücü ile değerlendirilir. Öz-yeterlik teorisi, insan etkinliğinin nasıl geliştirileceği ve artırılacağı konusunda açık rehberler sunmaktadır (Luszczynska, vd., 2005).

Bu çalışma, Aypay (2010) tarafindan Türkçe'ye uyarlanan Genel Öz-Yeterlik Ölçeği'nin (GÖYÖ) sağlık ve sosyal hizmet çalışanları örnekleminde Doğrulayıcı Faktör Analizi'nin (DFA) gerçekleştirilmesi amacıyla yapılmıştır. Diğer bir ifade ile ilgili ölçeğin yapı geçerliliğinin incelenmesi amacı taşımaktadır. $\mathrm{Bu}$ amaç doğrultusunda ölçek ile ilgili geçerlilik ve güvenirlik analizleri gerçekleştirilmiştir.

\section{Gereç ve Yöntem}

Aypay (2010) tarafindan geçerlilik ve güvenirliği yapılan GÖYÖ’nün birçok araştırmada hali hazırda kullanıldı̆̆ 1 görülmektedir (Öncel, 2014; Öntaş ve Tekindal, 2015; Binay ve Yiğit, 2016; Gökçearslan ve ark., 2016; Güngör ve Özdemir, 2017; Karaçam ve Pulur, 2017; Şahin, 2017; Çelik ve Koçak, 2018; Bingöl ve ark., 2019; Karakaya ve Özgür, 2019). Bununla birlikte bahse konu bu çalışmalarda Aypay (2010) tarafindan ortaya konulan yapının doğrulanması gerçekleştirilmemiştir. Literatürde bu tür durumlar eleştirilmektedir. Örneğin Fietzer ve Ponterotto (2015), Dean (2009) tarafindan geçerlilik ve güvenirliği yapılan Sosyal Adalet Savunuculuğu Ölçeği'ne DFA yapılmamasını eleş̧irmekte ve bu tür ölçeklerin farklı örneklemler üzerinde uygulanırken yeniden doğrulanmasını önermektedir. Literatürde çeşitli çalışmalarda geçerlilik ve güvenirlik çalışması yapılan ancak ortaya konulan yapının doğrulanması yapılmayan çalışmaların farklı örneklemlerde tekrar ele alınarak DFA'nın yapıldığı görülmektedir (Glozah ve Pevalin, 2015; Shayan ve ark., 2015; Lundin ve ark., 2016; Wong ve O'Driscoll, 2016; Romppel ve ark., 2017; Motamed ve ark., 2018; Tabatabaei ve Rasouli, 2018; Hjelle ve ark., 2019). Bu araştırmada, GÖYÖ’nün faktör yapısının sağlık ve sosyal hizmet çalışanları örneklemindeDFA'nın yapıldığı ilk çalışma olması açısından önem taşımaktadır.

Karasar (2015) araştırma modellerini tarama ve deneme modelleri olmak üzere ikiye ayırmaktadır. Bu araştırmada, ölçek geçerliliği ve güvenirliğini içerdiği için tarama modelli bir araştırmadır. Araştırmada katılımcılara uygun ve amaçlı örneklem yöntemleri ile ulaşılmıştır (Büyüköztürk, 2017). Literatürde DFA'nın kaç katılımcı ile yapılacağı ile ilgili çeşitli görüşler bulunmaktadır. Her ne kadar ölçek madde sayısının 10 katının yeterli olduğu (Bryman ve Cramer, 2001) ifade edilse de, Comrey ve Lee (1992) 300 kişilik katılımcı sayısını iyi olarak değerlendirmektedir.

Veri toplama araci olan ve 10 madde ve iki alt boyuttan oluşan GÖYÖ'nün geçerlilik ve güvenirlik analizleri Aypay (2010) tarafindan gerçekleştirilmiştir. Veri toplama aracı "Tamamen Yanlış", "Yanlış", "Doğru" ve "Tamamen Doğru" seçeneklerinden oluşan dörtlü Likert tipi bir ölçektir. Bu nedenle ölçekten en düşük 10 ve en yüksek 40 puan alınabilmektedir. Ölçekte ters puanlanan madde yer almamaktadır. Ölçekten alınan puanlar yükseldikçe özyeterliliğin de yükseldiği anlamına gelmektedir. Ölçek, yeni ve zor görevlerle başa çıkma yeterliliği inancını test etmektedir. Çaba ve Direnç alt boyutu 3, 4, 5, 7, 8, 10 maddelerinden, Yetenek ve Güven alt boyutu ise 1, 2, 6, 9 maddelerinden oluşmaktadır. Tüm ölçeğe ait Alpha değeri 0,83 ; Çaba ve Direnç alt boyutu için 0,79 ve Yetenek ve Güven için ise 0,63 değerleri elde edilmiştir. Ölçek hem toplam puan üzerinden hem de alt boyutlar üzerinden analize izin vermektedir.Araştırma kapsamında veriler online olarak toplanmıştır. Online anket hazırlamaya izin veren surveey.com sitesine hazırlanan anket formu yüklenmiştir. Yükleme işleminden sonra surveey.com sitesi anket formuna ulaşımı sağlayan link vermiş olup bu link katılımcılara gönderilmiştir. Anlık olarak anket girişleri takip edilmiş ve yeterli sayıya ulaşıldığında anket sonlandırılmıştır.

Yukarıda açıklananbilgiler doğrultusunda çalışma kapsamında 400 sağlık ve sosyal hizmet çalışanına ulaşılmıştır.Katılımcılara ait bilgiler Tablo 1'de verilmektedir. 
Tablo 1. Katılımcıların Sosyo-Demografik Bilgileri

\begin{tabular}{llllll}
\hline Değişkenler & $\mathbf{N}$ & $\mathbf{\%}$ & Değişkenler & $\mathbf{n}$ & $\mathbf{\%}$ \\
\hline Kadın & 235 & 58,8 & Lisans & 329 & 82,3 \\
\hline Erkek & 165 & 41,2 & Lisansüstü & 71 & 15,8 \\
\hline Toplam & $\mathbf{4 0 0}$ & $\mathbf{1 0 0 , 0}$ & Toplam & $\mathbf{4 0 0}$ & $\mathbf{1 0 0 , 0}$ \\
\hline Evli & 201 & 50,3 & Hemşire & 109 & 27,2 \\
\hline Bekâr & 199 & 49,7 & Hekim & 44 & 11,0 \\
\hline Toplam & $\mathbf{4 0 0}$ & $\mathbf{1 0 0 , 0}$ & $\begin{array}{l}\text { Idari } \\
\text { Personel }\end{array}$ & 105 & 26,2 \\
\hline & $\begin{array}{l}\text { Min- } \\
\text { Max }\end{array}$ & $\mathbf{x} \pm \mathbf{S S}$ & $\begin{array}{l}\text { Teknik } \\
\text { Personel }\end{array}$ & 59 & 14,8 \\
\hline Yaş & $21-$ & $32,53 \pm 8,42$ & $\begin{array}{l}\text { Sosyal } \\
\text { Hizmet }\end{array}$ & 83 & 20,8 \\
\hline $\begin{array}{l}\text { Çalışma } \\
\text { Süresi }\end{array}$ & $1-32$ & $7,48 \pm 7,56$ & Toplam & $\mathbf{4 0 0}$ & $\mathbf{1 0 0 , 0}$ \\
\hline
\end{tabular}

Araştırmaya katılanların \%58,8'i kadın, \%50,3'ü evli, \%82,3'ü lisans mezunu, \%27,2'si hemşire, \%26,2'si idari personel, \%20,8'1 sosyal hizmet çalışanıdır. Ayrıca katılımcıların en genci 21, en yaşlısı 60 yaşında veen tecrübeli çalışan da 32 yıllık bir deneyime sahiptir.

GÖYÖ’nün yapı geçerliliğini değerlendirirken çeşitli uyum indekslerinden yararlanılmıştır. Bu uyum indekslerine karar verirken literatürdeki çeşitli çalışmalar incelenerek karar verilmiştir (Doğan ve Başokçu, 2010; Aytaç ve Öngen, 2012; Kıraç, 2019;Kırlığlu ve Tekin, 2019; Tekin ve Kırlıoğlu, 2019; Kalayc1-Kırlığlu ve ark., 2020). Buna göre yap1 geçerliliğinin test edilmesinde Ki-kare istatistiği, GFI, CFI, IFI, SRMR, AGFI, NFI, NNFI, RMR ve RMSEA gibi uyum indeksleri tercih edilmiştir.

\section{Bulgular}

Araştırmanın amacı GÖYÖ’nün sağlık ve sosyal hizmet çalışanları örnekleminde DFA'sını gerçekleştirmek olduğundan bu bölümde öncelikle bu analize ilişkin bilgiler, ardından ise güvenirlik analizlerine ilişkin bilgiler verilecektir.

GÖYÖ’nün yapı geçerliliğinin test edebilmek için DFA'danyararlanılmıştır. DFA'nın amacı, önceden belirlenmiş veya teorik olarak arka planı olan bir yapının doğrulanmasıdır (Seçer, 2017; Yaşlıoğlu, 2017). Şekil 1'de iki boyutlu ve 10 maddeli GÖYÖ’nün t değerleri ve Şekil 2'de ise ilgili ölçeğin DFAsonuçları yer almaktadır.

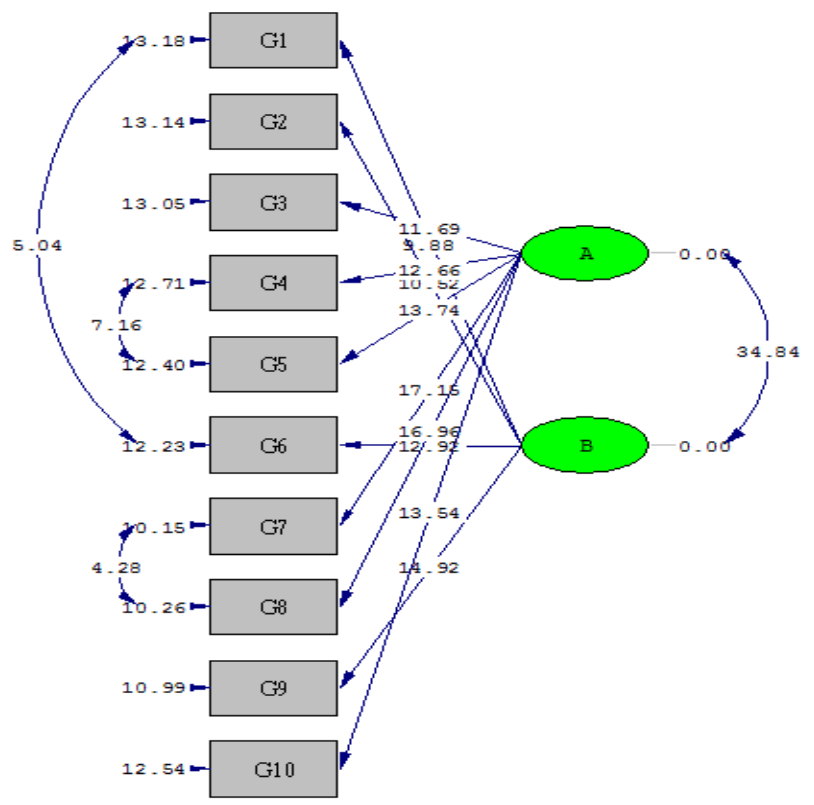

Şekil 1.GÖYÖ’ye ait DFA sonuçlarının t değerleri

LISREL programı aracılığı ile yapılan DFA sonuçları incelenirken maddelere ait $\mathrm{t}$ değerlerinin de yorumlanması gerekmektedir. LISREL programı araştırmacılara kolaylık sağlayarak eğer t değeri 1,96'nın altında kalan maddeleri kırmızı ile göstermekte ve bu konuda uyarı vermektedir. $\mathrm{Bu}$ uyarının amacı ise anlamlı olmayan maddelerin ölçekten çıkarılması $(p<0,05$ olmalıdır $)$ gerektiğine ilişkindir (Jöreskog ve Sorbom, 1996; Özüdoğru ve ark., 2018). DFA sonucunda GÖYÖ’ye ilişkin elde edilen $t$ değerlerinin $\mathrm{p}<0,01$ düzeyinde anlamlı olduğu tespit edilmiştir.

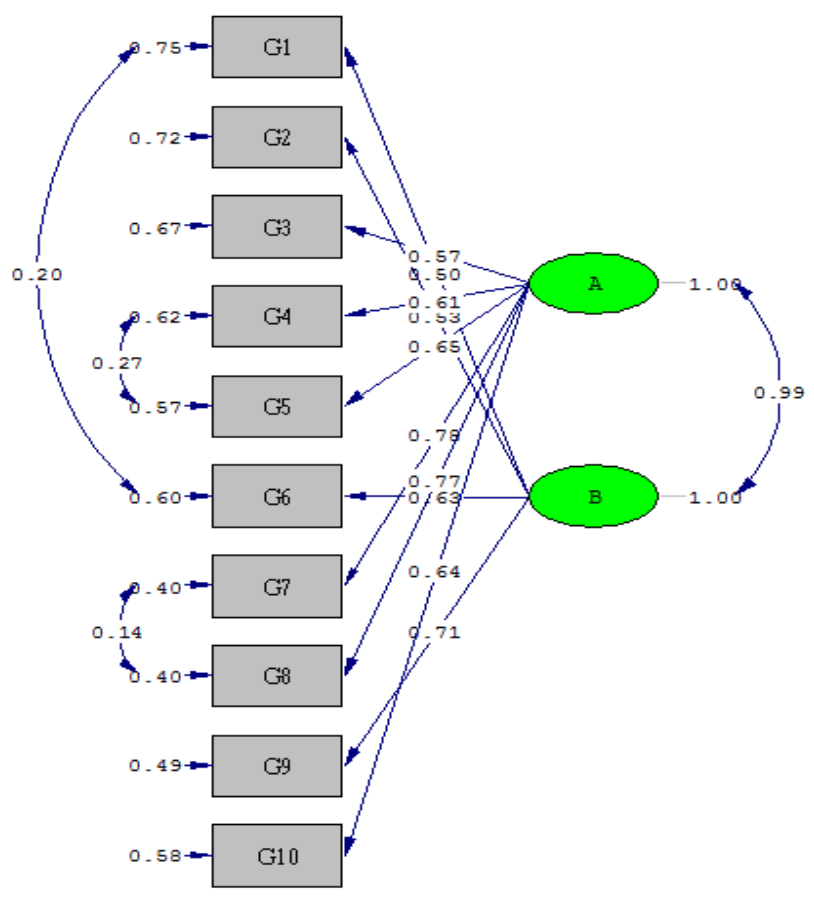

Şekil 2. GÖYÖ’ye ait DFA sonuçları

Şekil 2'de GÖYÖ’yeait DFA sonuçlarının standart çözümleri yer almaktadır. İki faktörlü ve 10 maddeli GÖYÖ’nün uyum indeksleri Tablo 2'de verilmektedir. 
Tablo 2. GÖYÖ’ye ait DFA sonuçlarının uyum indeksleri

\begin{tabular}{cccc}
\hline Uyum İndeksleri & Değer & Kabul & Mükemmel \\
\hline $\mathrm{X}^{2}$ (Ki-Kare) & 92,50 & - & - \\
Sd (Serbestlik & 31 & - & - \\
Derecesi) & & & $<2$ \\
$\mathrm{x}^{2} / \mathrm{Sd}$ & 2,98 & $<\mathbf{5}$ & $>\mathbf{0 , 9 5}$ \\
CFI & 0,98 & $>0,90$ & $>\mathbf{0 , 9 5}$ \\
GFI & 0,96 & $>0,90$ & $>0,95$ \\
AGFI & 0,92 & $>\mathbf{0 , 9 0}$ & $>\mathbf{0 , 9 5}$ \\
IFI & 0,98 & $>0,90$ & $<\mathbf{0 , 0 8}$ \\
RMSEA & 0,071 & $<0,10$ & $<\mathbf{0 , 5}$ \\
RMR & 0,013 & $<1,0$ & $\mathbf{0 , 0 0 - 0 , 0 5}$ \\
SRMR & 0,039 & $0,05-0,10$ & $>\mathbf{0 , 9 5}$ \\
NFI & 0,97 & $>0,90$ & $>\mathbf{0 , 9 5}$ \\
NNFI & 0,97 & $>0,90$ &
\end{tabular}

DFA'ya ait uyum indeksleri incelendiğinde $\mathrm{x}^{2}(92,50) / \mathrm{sd}(31)=2,98 ; \mathrm{CFI}=0,98 ; \mathrm{GFI}=0,96 ; \mathrm{AGFI}=0,92$; IFI=0,98; RMSEA $=0,071 ; \quad \mathrm{RMR}=0,013 ; \quad \mathrm{SRMR}=0,039$; $\mathrm{NFI}=0,97 ; \mathrm{NNFI}=0,97$ sonuçları elde edilmiştir.

Şekil 2'de de görüleceği üzere 1-6; 4-5 ve 7-8 maddeleri arasında kovaryans oluşturulmuştur. Kovaryans oluşturulurken LISREL programının modifikasyon önerileri dikkate alınmıştır. Modifikasyonların aynı alt boyu içerisinde maddeler arasında olmasında dikkat edilmiştir. (Hooper ve ark., 2008).

Tablo 3'te de GÖYÖ ve alt boyutlarına ilişkin yapılan analizde sonucu elde edilen Alpha değerleri gösterilmektedir.

Tablo 3.GÖYÖ ve alt boyutlarına ilişkin Alpha değerleri

\begin{tabular}{llc}
\hline \multicolumn{1}{c}{ Boyutlar } & \multicolumn{1}{c}{ Maddeler } & Alpha \\
\hline $\begin{array}{l}\text { Genel Öz-Yeterlik } \\
\text { Ölçeği }\end{array}$ & $1,2,3,4,5,6,7,8,9,10$ & 0,879 \\
\hline Çaba ve Direnç & $3,4,5,7,8,10$ & 0,846 \\
\hline Yetenek ve Güven & $1,2,6,9$ & 0,727 \\
\hline
\end{tabular}

Tablo 3 incelendiğinde GÖYÖ ve alt boyutlarının Alpha değerlerinin sırasıyla 0,$879 ; 0,846$ ve 0,727 olduğu tespit edilmiştir.

Tablo 4. GÖYÖ'nün madde analizleri

\begin{tabular}{ccc}
\hline Maddeler & $\begin{array}{c}\text { Madde-Toplam } \\
\text { Korelasyonu }\end{array}$ & $\begin{array}{c}\text { Madde Silindiğinde } \\
\text { Ölçek Alpha Değeri }\end{array}$ \\
\hline G1 & 0,500 & 0,874 \\
\hline G2 & 0,494 & 0,875 \\
\hline G3 & 0,536 & 0,872 \\
\hline G4 & 0,607 & 0,867 \\
\hline G5 & 0,625 & 0,865 \\
\hline G6 & 0,605 & 0,867 \\
\hline G7 & 0,735 & 0,857 \\
\hline G8 & 0,716 & 0,858 \\
\hline G9 & 0,634 & 0,865 \\
\hline G10 & 0,603 & 0,868 \\
\hline
\end{tabular}

Tablo 4'te GÖYÖ'ye ilişkin madde analizleri yer almaktadır. Maddelere ilişkin madde-toplam korelasyon değerlerinin en küçük 0,494 ve en büyük 0,735 olduğu tespit edilmiştir. Ayrıca madde çıkarıldığında Alpha en küçük 0,857 ve en büyük 0,875 değerlerini almaktadır.

Tablo 4. GÖYÖ’nün madde-toplam puan korelasyon değerleri

\section{चี તิં}

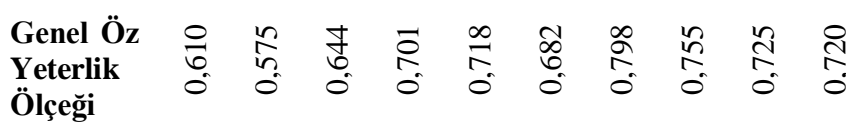

\begin{tabular}{|c|c|c|c|c|}
\hline $\begin{array}{l}\text { Çaba ve } \\
\text { Direnç }\end{array}$ & $\begin{array}{l}\bar{\infty} \\
0 \\
0\end{array}$ & $\stackrel{2}{2}$ & $\stackrel{2}{2}$ & \\
\hline
\end{tabular}

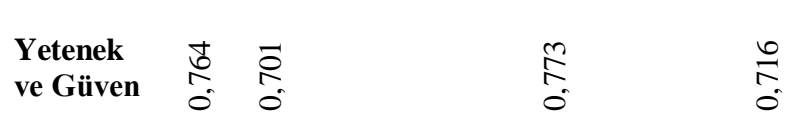

$\mathrm{p}=0,000$

Tablo 4'de her bir madde ile ölçekten alınan toplam puan arasındaki korelasyon değerleri yer almaktadır. Benzer şekilde her bir madde ile alt boyutlardan alınan toplam puan arasındaki korelasyon değerleri de incelenmiștir. Tablo 4'teki değerler incelendiğinde en küçük $r=0,575$ ve en büyük $\mathrm{r}=0,807$ arasında olduğu görülmektedir. Tüm korelasyon değerleri $\mathrm{p}<0,01$ düzeyinde anlamlı ve 0,50 değerinin üstündedir.

\section{Tartışma ve Sonuç}

Bu çalışmada Aypay (2010) tarafindan Türkçe'ye uyarlanan GÖYÖ'nün sağlık ve sosyal hizmet çalışanları örnekleminde DFA ile doğrulanması gerçekleştirilmiştir. DFA sonucunda GÖYÖ'ye ilişkin elde edilen $t$ değerlerinin $\mathrm{p}<0,01$ düzeyinde anlamlı olduğu tespit edilmiştir.CFI, GFI, IFI, RMSEA, RMR, SRMR, NFI ve NNFI değerlerinin literatürde belirtilen mükemmel uyum değerlerinin, $\mathrm{x} 2 /$ sd ve AGFI değerlerinin ise kabul edilebilir değerin üzerinde olduğu tespit edilmiştir (SchermellehEngel ve diğ., 2003; Schreiber ve diğ., 2006; Şimşek, 2007; Hooper ve ark., 2008). Literatürde bir ölçeğin Alpha değerinin $>0,70$ olması gerektiği belirtilmektedir (Nunnally ve Bernstein, 1994; Streiner, 2003; DeVellis 2016). Ölçek ve alt boyutlarına ilişkin değerlerin 0,70 'in üstünde olduğu tespit edilmiştir. Madde-toplam korelasyon değerinin 0,30 ve üzerinde olması gerekmektedir (Akduman ve Cantürk, 2010). Elde edilen değerlerin hepsi 0,30'un üzerinde olduğu görülmektedir. Ayrıca herhangi bir madde çıkarıldığında çıkarılan madde ölçeğin Alpha değerini yükseltiyorsa o maddenin ölçeğin güvenirliğine zarar verdiği ve bu nedenle de ölçekten atılması gerektiği ifade edilmektedir (Büyüköztürk, 2017; Doering ve ark 2018). Maddeler incelendiğinde herhangi bir maddenin çıkarılması durumunda ölçeğe ait Alpha değerinin (Alpha=0,879) üzerine çıkmadığı görülmektedir. Diğer taraftan maddetoplam puan arasındaki korelasyon değerlerinin anlamlı ve 0,50'nin üzerinde olması gerektiği ifade edilmektedir 
(Ercan ve İsmet 2004; Büyüköztürk, 2011; Karasar 2016). Aksi takdirde ilgili maddenin ölçekten çıkarılması gerekmektedir. Hem her bir madde ile ölçekten alınan toplam puan arasındaki korelasyon değerleri hem de her bir madde ile alt boyutlardan alınan toplam puan arasındaki korelasyon değerleri 0,50 'den büyük ve $\mathrm{p}<0,01$ düzeyinde anlamlidir.

Olumlu bir öz yeterlilik algısı bireyin eyleme-harekete geçmesini kolaylaştırmaktadır (Erol ve Avc1-Temizer, 2016). Diğer bir ifade ile olumlu öz yeterliliğin başarılı olma yolunda cesaretlendirici olduğu, olumsuz öz yeterliliğin pes etme ile ilişkilendirildiği belirtilmektedir (Yılmaz ve ark., 2007). Ek olarak kısa sürede sonuca ulaşma noktasında öz yeterliliğin önemli bir etkisi olduğu ifade edilmektedir (Akkuş, 2013). Sağlık ve sosyal hizmet çalışanlarının da çalışma koşulları ve iş yükleri düşünüldüğünde öz yeterlilik karşılaşılan stresli durumlar karşısında önemli bir kavram olarak karşımıza çıkmaktadır. Çalışma sonucunda da Aypay (2010) tarafindan Türkçe’ye uyarlanan ölçeğin sağlık ve sosyal hizmet çalışanları üzerinde yapı geçerliliği doğrulanmış ve de sağlık ve sosyal hizmet çalışanları örnekleminde kullanılabileceği sonucuna ulaşılmıştır.

\section{Kaynakça}

Akduman, G. G. \& Cantürk, G. (2010). Cinsel istismara uğrayan çocuklara karşı tutum ölçeği geçerlik ve güvenirlik çalışması (Üniversite öğrencileri örneklemi). Adli Tlp Dergisi, 24(2), 22-29.

Akkuş, Z. (2013). Sosyal bilgiler öğretmen adaylarının özyeterlik inanç düzeylerinin belirlenmesi üzerine bir çalışma. Dicle Üniversitesi Ziya Gökalp Ĕğitim Fakültesi Dergisi, 20, 102-116.

Aypay, A. (2010). Genel Öz Yeterlik Ölçeği’nin (GÖYÖ) Türkçe'ye Uyarlama Çalışması. İn̈̈nü Üniversitesi Ĕ̌itim Fakültesi Dergisi, 11(2), 113-132.

Aytaç, M. \& Öngen, B. (2012). Doğrulayıcı faktör analizi ile yeni çevresel paradigma ölçeğinin yap1 geçerliliğinin incelenmesi. Istatistikçiler Dergisi: İstatistik ve Aktüerya, 5(1), 14-22.

Bandura, A. (1986). Social foundations of thought and action: A social cognitive theory.

Bandura, A. (1997). Self-efficacy: The exercise of control. New York: Freem.

Bandura, A. (2002). Social cognitive theory in cultural context. Journal of Applied Psychology: An International Review, 51, 269-290.

Binay, Ş., \& Yiğit, R. (2016). Relationship Between Adolescents' Health Promoting Lifestyle Behaviors and Self-Efficacy. Journal of Pediatric Research, 3, 180-186.

Bingöl, T. Y., Batik, M. V., Hosoglu, R., \& Firinci Kodaz, A. (2019). Psychological Resilience and Positivity as Predictors of Self-Efficacy. Asian Journal of Education and Training, 5(1), 63-69.
Bryman, A. Cramer, D. (2001). Quantitative data analysiswith SPSS release 10 for Windows. London: RoutledgePress.

Comrey, A. L. \& Lee, H. B. (1992). A firstcourse in factoranalysis.

Hillsdale, NJ: Lawrence ErlbaumAssociates, Inc.

Çelik, E., \& Koçak, L. (2018). Suppression Effect of Sensation Seeking on the Relationship between General Self-Efficacy and Life Satisfaction among Emerging Adults. International Journal of Instruction, 11(4), 337-352.

Dean, J. K. (2009). Quantifying social justice advocacy competency: Development of the social justice advocacy scale. Dissertation Abstracts International Section A: Humanities and Social Sciences, 69 (12A), 4638.

DeVellis, R. F. (2016). Scale development: Theory and applications (Vol. 26). London: Sage Publications.

Doering, B. K., Barke, A., Friehs, T., \& Eisma, M. C. (2018). Assessment of grief-related rumination: validation of the German version of the Utrecht Grief Rumination Scale (UGRS). BMC psychiatry, 18(1), 43-53.

Doğan, N., \& Başokçu, T. O. (2010). İstatistik tutum ölçeği için uygulanan faktör analizi ve aşamalı kümeleme analizi sonuçlarının karşılaştırılması. Eğitimde ve Psikolojide Ölçme ve Değerlendirme Dergisi, 1(2), 65-71.

Eden, D. (2001). Means efficacy: External sources of general and specific subjective efficacy.In M. Erez, U. Kleinbeck, \& H. Thierry (Eds.), Work motivation in the context of a globalizing economy. Hillsdale, NJ: Lawrence Erlbaum

Englewood Cliffs, NJ: Prentice Hall

Erol, M., Avc1-Temizer, D. (2016). Eyleme geçiren bir katalizör "öz yeterlik algısı": Üniversite öğrencileri üzerine bir inceleme. Hacettepe Üniversitesi Eğitim Fakültesi Dergisi, 31(4) 711-723.

Fietzer, A. W., \& Ponterotto, J. (2015). A psychometric review of instruments for social justice and advocacy attitudes. Journal for Social Action in Counseling \& Psychology, 7(1), 19-40.

Glozah, F. N., \& Pevalin, D. J. (2015). Factor structure and psychometric properties of the General Health Questionnaire (GHQ-12) among Ghanaian adolescents. Journal of Child \& Adolescent Mental Health, 27(1), 53-57.

Gökçearslan, Ş., Mumcu, F. K., Haşlaman, T., \& Çevik, Y. D. (2016). Modelling smartphone addiction: The role of smartphone usage, self-regulation, general self-efficacy and cyberloafing in university students. Computers in Human Behavior, 63, 639649.

Güngör, S., \& Özdemir, Y. (2017). Perceived Teacher SelfEfficacy of Teacher Candidates Enrolled in the Pedagogical Formation Certificate 
Program. International Journal of Higher Education, 6(6), 112-128.

Hjelle, E. G., Bragstad, L. K., Zucknick, M., Kirkevold, M., Thommessen, B., \& Sveen, U. (2019). The General Health Questionnaire-28 (GHQ-28) as an outcome measurement in a randomized controlled trial in a Norwegian stroke population. BMC psychology, 7(1), 18.

Hooper, D., Coughlan, J., \& Mullen, M. (2008). Structural equation modelling: Guidelines for determining model fit. The Electronic Journal of Business Research Methods, 6(1), 53-60.

Judge, T. A., Erez, A. \& Bono, J. A. (1998). The power of being positive: The relation betweenpositive selfconcept and job performance. Human Performance, $11,167-187$

Kalaycı-Kırlığlu, H.İ., Daşbaş, S., \& Karakuş, Ö. (2020). Sosyal Hizmet Uygulamasinda Mesleki Uygunluk Ölçeği: Geçerlilik ve Güvenirlik. Toplum ve Sosyal Hizmet, 31(3), 793-822.

Karaçam, A., \& Pulur, A. (2017). Examining the relationship between referee self-efficacy and general self-efficacy levels of basketball referees in terms of certain variables. Journal of Education and Training Studies, 5(8), 37-45.

Karakaya, D., \& Özgür, G. (2019). Effect of a SolutionFocused Approach on Self-Efficacy and Self-Esteem in Turkish Adolescents With AttentionDeficit/Hyperactivity Disorder. Journal of Psychosocial Nursing \& Mental Health Services, 57(11), 45-55.

Karasar, N. (2016). Bilimsel araştırma yöntemi: Kavramlar, ilkeler, teknikler. Ankara: Nobel Yayınları.

Kıraç, R. (2019). Nomofobinin Dikkat Eksikliğine Etkisi. OPUS Uluslararası Toplum Araştırmaları Dergisi, 14(20), 1-1.

Kırlığlu, M., \& Tekin, H. H. (2019). Sosyal Adalet Savunuculuğu Ölçeğinin (SASÖ) Doğrulayıc1 Faktör Analizi. Dokuz Eylül Üniversitesi Sosyal Bilimler Enstitüsü Dergisi, 21(3), 859-874.

Lundin, A., Hallgren, M., Theobald, H., Hellgren, C., \& Torgén, M. (2016). Validity of the 12-item version of the General Health Questionnaire in detecting depression in the general population. Public Health, 136, 66-74.

Luszczynska, A., Scholz, U. \& Schwarzer, R. (2005). The General Self-Efficacy Scale: Multicultural Validation Studies, The Journal of Psychology, 139(5): 439-457.

Motamed, N., Zakeri, S. E., Rabiee, B., Maadi, M., Khonsari, M. R., Keyvani, H., \& Zamani, F. (2018). The Factor Structure of the Twelve Items General Health Questionnaire (GHQ-12): a Population Based Study. Applied Research in Quality of Life, 13(2), 303-316
Nunnally, J. C., \& Bernstein, I. (1994). Psychometric theory. New York: McGraw-Hill.

Öncel, L. (2014). Career adapt-abilities scale: Convergent validity of subscale scores. Journal of Vocational Behavior, 85(1), 13-17.

Öntaş, Ö. C., \& Tekindal, M. T. (2015). The effect of group work on the self-efficacy of social work students. Procedia-Social and Behavioral Sciences, 174, 1124-1128.

Recepoğlu, E., \& Tümlü, G. Ü. (2015). Üniversite akademik personelinin mesleki ve yaşam doyumlari arasindaki ilişkinin incelenmesi. Kastamonu Eğitim Dergisi, 23(4), 1851-1868.

Romppel, M., Hinz, A., Finck, C., Young, J., Brähler, E., \& Glaesmer, H. (2017). Cross-cultural measurement invariance of the General Health Questionnaire-12 in a German and a Colombian population sample. International journal of methods in psychiatric research, 26(4), e1532.

Schermelleh-Engel, K., Moosbrugger, H., \& Müller, H. (2003). Evaluating the fit of structural equation models: Tests of significance and descriptive goodness-of-fit measures. Methods of psychological research online, $8(2), 23-74$.

Scholz, U., Doña, B. G., Sud, S. \& Schwarzer, R. (2002). Is General Self-Efficacy a Universal Construct? Psychometric Findings from 25 Countries, European Journal of Psychological Assessment, 18(3):242251.

Schreiber, J. B., Nora, A. \& Stage, F. K., Barlow, E. A., \& King, J. (2006). Reporting structural equation modeling and confirmatory factor analysis results: A review. The Journal of educational research, 99(6), 323-338.

Schwarzer, R. \& Jerusalem, M. (1995). Generalized SelfEfficacy Scale. In J. Weinman,S. Wright, \& M. Johnston (Eds.), Measures in health psychology: A user's portfolio. Causal and control beliefs (pp. 3537). Windsor, England: NFER-NELSON.

Seçer, İ. (2017). SPSS ve LISREL ile pratik veri analizi: Analiz ve raporlaştırma. Ankara: Anı Yayıncılık.

Shayan, Z., Pourmovahed, Z., Najafipour, F., Abdoli, A. M., Mohebpour, F., \& Najafipour, S. (2015). Factor structure of the General Health Questionnaire-28 (GHQ-28) from infertile women attending the Yazd Research and Clinical Center for Infertility. International Journal of Reproductive BioMedicine, 13(12), 801.

Sherer, M., Maddux, J. E., Mercandante, B., Prentice-dunn, S.,Jacobs, B. \& Rogers, R. W. (1982). The SelfEfficacy Scale: Construction And Validation, Psychological Reports,51,663-671.

Streiner, D. L. (2003). Starting at the beginning: an introduction to coefficient alpha and internal consistency. Journal of personality assessment, 80(1), 99-103. 
Şahin, H. (2017). Emotional Intelligence and Self-Esteem as Predictors of Teacher Self-Efficacy. Educational Research and Reviews, 12(22), 1107-1111.

Tabatabaei, S., \& Rasouli, Z. (2018). The Reliability and validity of Persian Version of the General Health Questionnaire (GHQ-60) in Industry Staff. Iran Occupational Health, 15(3), 45-54.

Tekin, H. H., \& Kırlığlu, M. (2019). Utrecht Yasa Bağlı Ruminasyon Ölçeği'nin (UYRÖ) Türkçe Versiyonunun Geçerlilik ve Güvenirliği. OPUS Uluslararası Toplum Araştırmaları Dergisi, 11(18), 1114-1135.

Wong, K. C., \& O’Driscoll, M. P. (2016). Psychometric properties of the General Health Questionnaire-12 in a sample of Hong Kong employees. Psychology, health \& medicine, 21(8), 975-980.

Wood, R., \& Bandura, A. (1989). Impact of conceptions of ability on self-regulatory mechanisms and complex
Şimşek, Ö. F. (2007). Yapısal eşitlik modellemesine giriş: Ttemel ilkeler ve LISREL uygulamaları. Ankara: Ekinoks Yayınları.

decision making. Journal of Personality and Social Psychology, 56, 407-415

Yaşlıoğlu, M. M. (2017). Sosyal bilimlerde faktör analizi ve geçerlilik: Keşfedici ve doğrulayıcı faktör analizlerinin kullanılması. Istanbul Üniversitesi İsletme Fakültesi Dergisi, 46, 74-85.

Yılmaz, M., Gürçay, D., \& Ekici, G. (2007). Akademik Özyeterlik Ölçeği'nin Türkçe'ye uyarlanması. Hacettepe Üniversitesi Ĕ̈itim Fakültesi Dergisi, 33, 253-259.

Zimmerman, B. J. (1995). Self-efficacy and educationaldevelopment. In: Self-efficacy in ChangingSocieties, Eds: Albert Bandura, New York: Cambridge University Press, pp. 202-231. 